\title{
Autonomic neuropathy in African diabetic patients
}

\author{
P.S. Tuch, G.V. Gill and K.R.L. Huddle \\ Department of Medicine, Baragwanath Hospital, University of Witwatersrand, PO Bertsham, \\ Johannesburg 2013, South Africa
}

\begin{abstract}
Summary: To determine the prevalence and extent of autonomic neuropathy amongst Africans with insulin-dependent diabetes mellitus (IDDM), we investigated 50 such patients at our clinic. Mean age ( \pm 1 s.d.) was $26 \pm 6$ years, male:female ratio was equal (25M:25F) and duration of diabetes was $4.0 \pm 3.0$ years. A battery of six validated tests of autonomic function was performed, testing both sympathetic and parasympathetic systems. Overall $16(32 \%)$ had evidence of autonomic damage, affecting parasympathetic only in 14, and both sympathetic and parasympathetic in two. Those with autonomic neuropathy had a significantly longer diabetes duration than those without $(6.0 \pm 2.8$ years versus $3.1 \pm 2.7$ years, $P<0.005)$, but there was no difference in glycosylated haemoglobin $\left(\mathrm{HbA}_{1}\right)$ between the two groups. Autonomic neuropathy was also not significantly associated with peripheral neuropathy or other diabetic complications. Autonomic neuropathy carries a poor prognosis in IDDM and this high prevalence in a group of patients with relatively short diabetes duration gives cause for concern.
\end{abstract}

\section{Introduction}

Autonomic neuropathy is an unusual but important manifestation of diabetic complications. Its importance has only been appreciated since effective clinical tests of cardiovascular responses to autonomic stimuli have been described. ${ }^{1}$ Using such criteria it has been demonstrated that autonomic neuropathy affects some $20-40 \%$ of the diabetic population, ${ }^{2,3}$ the parasympathetic system being involved first and the sympathetic later. ${ }^{4}$ Classical symptoms of autonomic neuropathy such as diarrhoea, vomiting, bladder dysfunction, postural dizziness and impotence, are clearly important, but they are relatively rare, and are also non-specific and poor indicators of overall autonomic neuropathy prevalence. ${ }^{3,4}$ One exception appears to be gustatory sweating, which seems quite specific to diabetes. ${ }^{5}$ Of great importance is the observation that the presence of autonomic neuropathy greatly worsens the prognosis of diabetes: the follow-up study by Ewing and colleagues ${ }^{6}$ suggested a $50 \%$ mortality risk at 5 years from diagnosis.

There is little information in the literature on autonomic neuropathy in Black African diabetes, apart from single reports on South African ${ }^{7}$ and Zambian ${ }^{8}$ patients. The latter study tested patients by electrocardiogram (ECG) $R-R$ changes during

Correspondence: G.V. Gill, M.Sc., M.D., F.R.C.P., D.T.M.\&H., The Diabetes Centre, Walton Hospital, Rice Lane, Liverpool L9 1AE, UK

Accepted: 2 August 1993 deep breathing but only those with a postural drop of blood pressure on standing were investigated. This is likely to account for the small number $(11 / 600$ or $1.8 \%)$ of positive cases. This study is of interest, however, in that $44 \%$ of patients were impotent, compared with $22 \%$ of controls, though $26 \%$ of the impotent diabetics were on antihypertensive drug treatment.

The South African study ${ }^{7}$ was of 70 diabetic patients at our own hospital, reported in 1977. The patients were of mixed type, though most $(84 \%)$ were 'maturity onset'. Five tests of autonomic function were performed including postural blood pressure drop, blood pressure response to handgrip and pulse rate response to the Valsalva manoeuvre. Resting heart rate and sinus arrhythmia were also tested. Some tests were not standardized in the way of more recent studies. Diagnostic criteria were also low (for example, a $10 \mathrm{~mm}$ drop of blood pressure on standing was taken as positive), and this together with the older onset of diabetes may explain the very high prevalence of $72 \%$ with supposed autonomic neuropathy.

Our study was therefore defined to look at a group of young insulin-dependent diabetes mellitus (IDDM) patients only, using modern validated tests of autonomic function. ${ }^{9}$

\section{Patients and methods}

Fifty patients were chosen from the Diabetic Clinic of Baragwanath Hospital in Soweto, South Africa. 
Health care in South Africa is no longer segregated, but the township of Soweto, served by the clinic, remains exclusively Black. The patients were thus indigenous Black South Africans, of varying tribal origin, but predominantly Zulu. Effective diabetes care and supply of insulin is available only from Baragwanath Hospital; the clinic therefore treats all local diabetics and there is no selection or referral bias in studies such as this. The 50 patients fulfilled World Health Organisation criteria for the diagnosis of diabetes mellitus ${ }^{10}$ and had typical insulin-dependent (IDDM, Type 1) diabetes. Age of onset was below 30 years, all had presented abruptly or in ketosis, and had required insulin treatment from diagnosis. The patients for study were chosen simply as consecutive attenders fulfilling these criteria for true IDDM. Patients with medical conditions potentially interfering with cardiac or autonomic function were excluded (for example, angina, heart failure, hypertension, other cardiac disease, malnutrition, alcoholism, renal failure or significant neurological disease), as well as those on drugs which might interfere with autonomic function tests. Patients were investigated and assessed as follows: a. A questionnaire was filled in with the patient to determine the presence of symptoms of autonomic neuropathy. These were postural dizziness, vomiting, diarrhoea, bladder disturbance, abnormal sweating and impotence.

b. A full neurological examination was carried out.

c. Blood was taken for glycosylated haemoglobin $\left(\mathrm{HbA}_{1}\right.$; local non-diabetic reference range $5.0-8.0 \%$ ).

d. A battery of five autonomic functions tests were performed, as described by Ewing and Clarke ${ }^{1,4}$ and summarized in Table I.

The final assessment as to whether autonomic neuropathy was present and to what degree, was made according to the criteria in Table II. Patients were considered 'normal', 'borderline' or 'abnormal' according to their autonomic test results. Those in the abnormal group could be further subdivided into 'early parasympathetic damage' (Grade I), 'definite parasympathetic damage' (Grade II) and 'combined sympathetic and parasympathetic damage' (Grade III). In this young age group, we defined 'peripheral neuropathy' as any definite deficit in sensation (touch, pain, vibration

Table I Autonomic function tests performed and interpretation of results (after Ewing and Clarke, 1982)

\begin{tabular}{llccc}
\hline Test no. & \multicolumn{1}{c}{ Test } & Normal & Borderline & Abnormal \\
\hline 1 & $\begin{array}{l}\text { Parasympathetic function } \\
\text { Heart rate response to Valsalva } \\
\text { manoeuvre (ratio) }\end{array}$ & $>1.21$ & $1.11-1.20$ & $<1.10$ \\
2 & $\begin{array}{l}\text { Heart rate variation (R-R) during deep } \\
\text { breathing (difference between } \\
\text { maximum and minimum) }\end{array}$ & $>15 /$ minute & $11-14 /$ minute & $<10 /$ minute \\
3 & $\begin{array}{l}\text { Immediate heart rate response to } \\
\text { standing (30:15 R-R ratio) }\end{array}$ & $>1.04$ & $1.01-1.03$ & $<1.00$ \\
4 & $\begin{array}{l}\text { Sympathetic function } \\
\text { BP response to standing (fall in } \\
\text { systolic BP) }\end{array}$ & $<10 \mathrm{mmHg}$ & $11-29 \mathrm{mmHg}$ & $>30 \mathrm{mmHg}$ \\
\hline $\begin{array}{l}\text { BP response to sustained hand grip } \\
\text { (increase in diastolic BP) }\end{array}$ & $>16 \mathrm{mmHg}$ & $11-15 \mathrm{mmHg}$ & $<10 \mathrm{mmHg}$ \\
\hline
\end{tabular}

Table II Category of patients according to autonomic function tests

\begin{tabular}{llll}
\hline $\begin{array}{l}\text { Parasympathetic } \\
\text { test results }\end{array}$ & $\begin{array}{l}\text { Sympathetic } \\
\text { test results }\end{array}$ & Autonomic status & Grade \\
\hline Normal & Normal & Normal \\
One or more borderline & Normal & Borderline & \\
One abnormal & Normal & Early parasympathetic damage & I \\
Two or more abnormal & Normal & Definite parasympathetic damage II & II \\
Two or more abnormal & One or more abnormal & Combined sympathetic and & III \\
& & parasympathetic damage & \\
\hline
\end{tabular}


or joint position sense), motor function or tendon reflex (knee or ankle).

Results were expressed as means \pm standard deviation (s.d.) and significance was assessed by Student's $t$-test and the chi-squared test with Yates' correction.

\section{Results}

\section{(a) Clinical features}

Sex distribution, age, duration of diabetes and $\mathrm{HbA}_{1}$ levels are shown in Table III. Four had retinopathy $(8 \%)$ and $38(76 \%)$ had peripheral neuropathy. This consisted of a peripheral sensory deficit alone in 25 patients and a sensory deficit plus absent ankle reflexes in 13. No patients had significant painful neuropathy, ${ }^{11}$ amyotrophy ${ }^{12}$ or neuropathic cachexia. ${ }^{13}$

\section{(b) Autonomic function tests}

These were considered positive in 16 patients $(32 \%)$ (see Table III). Four ( $8 \%$ ) had borderline tests and in $30(60 \%)$ the tests were normal.

Table III Clinical features, complications and results of autonomic neuropathy tests (mean \pm s.d.)

\begin{tabular}{ll}
\hline Number & 50 \\
Sex & $25 \mathrm{M}: 25 \mathrm{~F}$ \\
Age (years) & $26 \pm 6$ (range 14-39) \\
Duration of diabetes & $4.0 \pm 3.0$ (range $0.1-11.0)$ \\
$\quad$ (years) & $9.4 \pm 1.8$ \\
HbA $_{1}(\%)$ & $4(8 \%)$ retinopathy \\
Complications & $38(76 \%)$ neuropathy \\
& 12 \\
Autonomic tests* & 2 \\
$\quad$ Grade I & 2 \\
$\quad$ Grade II & Grade III \\
$\quad$ Total & $16(32 \%)$ \\
\hline
\end{tabular}

${ }^{*}$ Grade $\mathrm{I}=$ early parasympathetic damage; Grade $\mathrm{II}=$ definite parasympathetic damage; Grade III = combined sympathetic and parasympathetic damage.

\section{(c) Characteristics of group with autonomic neuropathy}

Table IV compares those with and without positive tests of autonomic function. Sex distribution, age and mean $\mathrm{HbA}_{1}$ were not significantly different between the two groups. The duration of diabetes was, however, significantly longer in those with autonomic neuropathy $(6.0 \pm 2.8$ years versus $3.1 \pm 2.7$ years, $P<0.0005)$. Only two patients with diabetes of duration less than 4.0 years had autonomic neuropathy.

\section{(d) Symptoms of autonomic neuropathy}

Symptoms compatible with autonomic neuropathy were present in 22 patients $(44 \%)$, but only nine of these $(41 \%)$ had abnormal autonomic tests. Conversely, of the 16 with abnormal tests only nine $(50 \%)$ had symptoms. Analysis by the chi-squared test showed no significant association between symptoms and test results.

\section{(e) Relationship between autonomic and peripheral neuropathy}

Of the 16 patients with definite autonomic neuropathy, $14(87 \%)$ had evidence of peripheral neuropathy. Of the 34 patients without autonomic neuropathy, however, 24 (71\%) also had peripheral neuropathy. Again, analysis by the chi-squared test failed to show a significant association between peripheral and autonomic neuropathy.

\section{Discussion}

The findings of a $32 \%$ prevalence of confirmed autonomic neuropathy amongst our IDDM population, are in accord with other estimates as previously mentioned. ${ }^{2,3}$ Most of our patients had early parasympathetic damage (12 out of 16 ), but two had more advanced damage and two also had sympathetic dysfunction. The patients with autonomic neuropathy had a significantly longer duration of diabetes that those without. This is in

Table IV Comparison of patients with and without autonomic neuropathy

\begin{tabular}{lccclc}
\hline & Number & Sex & Age (years) & Duration of diabetes (years) & Hb $A_{1}(\%)$ \\
\hline Autonomic neuropathy & $16(32 \%)$ & M7:F9 & $28 \pm 5$ & $6.0 \pm 2.8$ (range 1.4-11.0)* & $9.4 \pm 1.8$ \\
$\begin{array}{l}\text { No autonomic } \\
\text { neuropathy }\end{array}$ & $34(68 \%)$ & M18:F16 & $25 \pm 7$ & $3.1 \pm 2.6$ (range 0.1-11.0) & $9.5 \pm 1.9$ \\
\begin{tabular}{l} 
Significance \\
\hline
\end{tabular} & & NS & NS & $P<0.005$ & NS \\
\hline
\end{tabular}

*Only two of the autonomic neuropathy group had a duration of diabetes below 4.0 years. NS, not significant. 
agreement with other studies.,14 However, the duration of diabetes in our patients was relatively short (overall mean $4.0 \pm 3.0$ years), though it is known that autonomic neuropathy can occur in diabetic patients of less than 2 years duration. ${ }^{\text {is }}$

There is a known relationship between peripheral and autonomic neuropathy, ${ }^{16,17}$ some suggesting that peripheral nerve dysfunction is present in all cases of autonomic neuropathy. ${ }^{18}$ Overall $87 \%$ of our group with autonomic neuropathy had associated peripheral neuropathy, but the figure for those without autonomic neuropathy was also high at $71 \%$ and the difference was not significant. Because of the higher overall prevalence of peripheral neuropathy $(76 \%)$, we would presumably require larger numbers to demonstrate an association. Similarly our prevalence of retinopathy was too small to allow us to attempt correlation with autonomic neuropathy.

As has been mentioned, symptoms of autonomic neuropathy are non-specific, ${ }^{3,4}$ and our results confirm this with suggestive symptoms present in only $41 \%$ of patients with autonomic neuropathy and also in $38 \%$ of those without.

The actual cause of diabetic neuropathy is still unknown, but it is widely thought to be related to prolonged poor glycaemic control and frequently ameliorates with improved control. ${ }^{19,20}$ Such

\section{References}

1. Ewing, D.J. Practical bedside investigation of diabetic autonomic failure. In: Bannister, R. (ed.) Autonomic Failure. Oxford University Press, Oxford, 1983, pp. 371-405.

2. Dyrberg, T., Benn, J., Sandahl Cristiansen, J. \& Hilsted, J. Prevalence of diabetic autonomic neuropathy measured by simple bedside tests. Diabetologia 1981, 20: 190-194.

3. Clarke, B.F., Ewing, D.J. \& Campbell, I.W. Diabetic autonomic neuropathy. Diabetologia 1979, 17: 195-212.

4. Ewing, D.J. \& Clarke, B.F. Diagnosis and management of diabetic autonomic neuropathy. $B r$ Med $J$ 1980, 185: 916-918.

5. Watkins, P.J. Facial sweating after food: a new sign of autonomic neuropathy. $\mathrm{Br}$ Med J 1973, 4: 584-586.

6. Ewing, D.J., Campbell, I.W. \& Clarke, B.F. The natural history of diabetic autonomic neuropathy. $Q J$ Med 1980 , 193: $95-108$.

7. Morley, J.E., Asvat, M.S., Klein, C. \& Lowenthal, M.N. Autonomic neuropathy in black diabetic patients. $S$ Afr Med $J$ 1977, 52: 115-116

8. Rolfe, M. The neurology of diabetes mellitus in Central Africa. Diabetic Med 1988, 5: 399-401.

9. Tuch, P.S. Diabetic autonomic neuropathy in black insulindependent diabetics under forty years. M. Med. Thesis University of Witwatersrand, 1985.

10. World Health Organisation. Diabetes Mellitus - Report of a WHO Study Group. WHO Technical Report Series 727. World Health Organisation, Geneva, 1985.

11. Archer, A.G., Watkins, P.J., Thomas, P.K., Sharma, A.K. \& Payan, J. The natural history of acute painful neuropathy in diabetes mellitus. $J$ Neurol Neurosurg Psychiat 1983, 46: 491-499.

12. Coppack, S.W. \& Watkins, P.J. The natural history of diabetic femoral neuropathy. $Q J$ Med 1991, 79: 307-313. studies, however, are concerned with peripheral rather than autonomic neuropathy. The latter does not often improve or resolve in the same way as peripheral neuropathy ${ }^{6}$ and may possibly be due to different underlying processes. In this context it is of interest that overall glycaemic control, as measured by current $\mathbf{H b A}_{1}$ levels, was similar in those with and without autonomic neuropathy in our series. A recent Swedish study, ${ }^{21}$ and particularly the American DCCT study ${ }^{22}$ have confirmed the strong association of glycaemic control with complication risk in IDDM. In the latter study, ${ }^{22}$ autonomic function tests were performed and the risk of development of autonomic neuropathy was reduced in the cohort with intensified glycaemic control.

The autonomic function tests we used are not technically difficult to perform, though the full battery of five tests is relatively time-consuming. Nevertheless, there is no doubt that to properly assess the prevalence of autonomic neuropathy, this type of screening has to be performed. Our prevalence of $32 \%$ in young Sowetan IDDM patients, at an average duration of only 6 years, is of considerable concern, particularly in view of the gloomy prognosis of autonomic neuropathy, with over half dying at 5 years from diagnosis. ${ }^{6}$

13. Ellenberg, M. Diabetic neuropathic cachexia. Diabetes 1974 , 23: 418-423.

14. Watkins, P.J. \& Edmonds, M.E. Clinical presentation of diabetic autonomic failure. In: Bannister, R. (ed.) Autonomic Failure. Oxford University Press, Oxford, 1983, pp. 337-370.

15. Pfeifer, M.A., Weinberg, C.R., Cook, D.L. et al. Autonomic neural dysfunction in recently diagnosed diabetic subjects. Diabetes Care 1984, 7: 447-453.

16. Burke, C.M., O‘Connell, B.M., O’Doherty, A., Devlin, S.G. \& Flanagan, A. Autonomic neuropathy in a diabetic clinic. Irish Med J 1984, 77: 202-205.

17. Ewing, D.J., Burt, A.A. \& Williams, I.R.C. Peripheral motor nerve function in diabetic autonomic neuropathy. $J$ Neurol Neurosurg Psychiat 1976, 29: 453-460.

18. Lloyd-Mostyn, R.U. \& Watkins, P.J. Defective innervation of the heart in diabetic autonomic neuropathy. Br Med J 1975, 3: 15- 17.

19. Pirart, J. Diabetes mellitus and its degenerative complications; a prospective study of 4,400 patients observed between 1947 and 1973. Diabetes Care 1978, 1: 168-188.

20. Boulton, A.J.M., Drury, J., Clarke, B. \& Ward, D.J. Continuous subcutaneous insulin infusion in the management of painful diabetic neuropathy. Diabetes Care 1982, 5: 386-390.

21. Reichard, P., Nilsson, B. \& Rosenqvist, U. The effect of long-term intensified insulin treatment on the development of microvascular complications of diabetes mellitus. $N$ Engl J Med 1993, 329: 304-309.

22. Diabetes Control and Complications Trial Research Group. The effect of intensive treatment of diabetes on the development and progression of long-term complications in insulindependent diabetes mellitus. $N$ Engl $J$ Med 1993, 329: 977-986. 